\title{
As políticas de formação de professores: a expansão comprometida
}

\author{
Olgaíses Mavés \\ Universidade Federal do Pará \\ Stella Segenreich \\ Universidade Católica de Petrópolis \\ Celia Otranto \\ Universidade Federal Rural do Rio de Janeiro
}

\section{Resumo}

O texło é resultado de pesquisa bibliográfica e tem como objetivo apresentar a análise referente aos cursos de Formação de Professores de forma presencial e a distância, realizados em instituições tradicionais de formação docente, bem como nos Institutos Federais. Os dados indicam redução de matrículas nas instituições tradicionais, se contrapondo a uma grande ampliação de oferta nos Institutos Federais, o que pode minimizar a escassez de docentes, apesar dos riscos apontados neste estudo relacionados à oferta de licenciaturas por instituições sem tradição na área.

42 Palavras-chave: Formação de professores. Educação a distância. Institutos Federais.

\section{The policies of teacher education: the jeopardized expansion}

\section{Abstract}

The text is the result of literature research and aims to present the analysis for the Teacher Training courses both by attendance and at a distance performed in traditional institutions of teacher education, as well as the Federal Institutes. The data indicates a reduction in enrollment in traditional institutions, in contrast to a major expansion of the Federal Institutes offer, which can minimize the shortage of teachers, despite the risks highlighted in this study, related to offering undergraduate institutions without tradition in the area.

Keywords: Teacher training. Distance education. Federal Institute of Education. Science and Technology. 


\section{Políticas para la formación del profesorado: la expansión comprometida}

\section{Resumen}

El texto es el resultado de la investigación de la literatura y tiene como objetivo presentar el análisis de los cursos de formación de profesores de forma presencial y a distancia en las instituciones tradicionales de la formación del profesorado, así como los Institutos Federales. Los datos indican una reducción de la matrícula en las instituciones tradicionales, en contraste con una importante expansión de la oferta Institutos Federal, que puede minimizar la escassez de maestros, a pesar de los riesgos señalados en este estudio, en relación con las instituciones oferentes de pregrado sin tradición en la zona. Palabras clave: Formación del profesorado. Educación a distancia. Instituto Federal de Educación, Ciencia y Tecnología.

A crise estrutural do capitalismo que está presente no mundo, desde o final do século XX, vem exigindo que os países desenvolvidos invistam mais na educação superior, para fazer face à reestruturação produtiva e ao desemprego decorrente desse status quo. Segundo Mészáros (2002), o mundo vive uma crise sem precedentes, atingindo todas as dimensões do capitalismo: produção, consumo e circulação/distribuição. Contudo, esse fenômeno não está restrito à esfera socioeconômica, atingindo, também, o sistema de valores e as instituições que, tradicionalmente, os reproduzem. Para esse autor, "A crise estrutural da educação tem estado em evidência há já um número de anos nada desprezível. E aprofunda-se a cada dia, ainda que esta intensificação não assuma a forma de confrontações espetaculares" (MÉSZÁROS, 2002, p. 995).

Para alguns Organismos Internacionais, a educação desempenha um papel importante no processo da saída da crise estrutural. A Organização para Cooperação e Desenvolvimento Econômico (OCDE), por exemplo, deixa claro, em documento intitulado Panorama sobre a Educação, o papel do ensino superior como uma ferramenta fundamental para o desenvolvimento econômico. Esse organismo vê o papel desse nível de ensino como meio de mobilidade e ascensão social, indicando que as taxas de emprego são maiores, cerca de $85 \%$, para aqueles que têm o ensino superior, assim como para o salário, representando um ganho de até $157 \%$ para as pessoas na faixa etária 
As políticas de formação de professores: a expansão comprometida

de 25 a 64 anos em relação àquelas que só alcançaram o ensino médio (OCDE, 2013).

Da mesma forma, o Banco Mundial (1994) tem indicado o papel do Ensino Superior para o "alivio da pobreza", enfatizando que esse nível de ensino tem a responsabilidade de formar pessoas que devem desempenhar cargos de responsabilidade nos setores públicos e privados, forjando a identidade nacional, contribuindo para o aumento da produtividade do trabalho, e para o crescimento econômico.

Brasil, apesar dos avanços tidos nos últimos anos, ainda apresenta um panorama insatisfatório, no tocante a esse nível de ensino. $\bigcirc$ Censo da Educação Superior de 2012 nos informa que o país tem 2.416 Instituições de Ensino Superior, 7.261.801 matrículas nos cursos de graduação e pós-graduação, tendo as IES privadas uma participação de $73 \%$ das matrículas de graduação. A taxa líquida, que corresponde a faixa etária de 18 a 24 anos, ainda está abaixo de 15\%, o que deixa o país atrás da grande maioria dos vizinhos da América Latina, como é o caso da Argentina, do Chile e do Uruguai.

Em face dessa conjuntura de crise, o Brasil tem adotado algumas medidas visando à expansão do ensino superior. Os governos de Fernando Henrique Cardoso (1 995-2002) e Luiz Inácio Lula da Silva (2003-2010), em um passado recente, estabeleceram alguns marcos regulatórios para possibilitar o ingresso no nível superior de um maior número de pessoas.

$\bigcirc$ governo de Fernando Henrique Cardoso notabilizou-se pela Reforma do Estado que efetivou em 1995, com o objetivo, segundo os reformadores, de tornar esse ente menos burocrático, passando a assumir um estilo gerencial e avaliador. Para tanto, houve uma intensa privatização de empresas públicas, criou-se a figura do público não estatal e o ensino superior foi elevado ao estatuto de "atividade não exclusiva do Estado", acentuando ainda mais a privatização desse nível de ensino. Destacam-se nesse governo três grandes marcos regulatórios: a Lei n 9.394, de 20 de dezembro 1996 (BRASIL, 1996), que dedica o capítulo IV à Educação Superior e no artigo 44 indica que este abrangerá os cursos sequenciais por campo de saber; de graduação, de pós-graduação, de extensão.

Mas é o Decreto-Lei n² 2.207, de 15 de abril 1997 (BRASIL, 1997), que, no artigo $4^{\circ}$, classifica as instituições de ensino superior em 
Universidades, Centros Universitários, Faculdades Integradas, Faculdades e Institutos Superiores ou Escolas Superiores. Pode-se dizer que essa legislação teve inspiração no documento do Banco Mundial La enseñanza superior. Las lecciones derivadas de la experiência (1994), que, dentre outras recomendações, indicava a necessidade dos países "diversificarem" as instituições de ensino superior. A importância desse ato foi a abertura que ocorreu para a criação de Faculdades privadas, havendo, com isso, uma expansão de vagas e matrículas nessa categoria administrativa, aumentando e aprofundando a privatização do ensino superior.

$\bigcirc$ último significativo marco regulatório que incidiu sobre o ensino superior, no governo de Fernando Henrique Cardoso, foi a aprovação do Plano Nacional de Educação, em 2001. Esse documento, que, na prática, não foi posto em execução, já deixava claro, no tocante à educação superior que "Nenhum país pode aspirar a ser desenvolvido e independente sem um forte sistema de educação superior" (BRASIL, 2001). Para tanto, apresentava como o primeiro objetivo referente a esse nível "Prover, até o final da década, a oferta de educação superior para, pelo menos $30 \%$ da faixa etária de 18 a 24 anos."

Apesar do aparato legal, a expansão do ensino superior, nesse período, ocorreu, principalmente, por meio das instituições privadas, não tendo havido apoio para a criação de outras universidades federais. Foi um período quando o setor público amargou a desventura do abandono por parte do governo central.

O governo Lula da Silva foi pródigo na legislação de indução à expansão do ensino superior. Os dados do Censo do Ensino Superior de 2012, indicam que, nos últimos 10 anos, as matrículas dobraram, passando de 3,5 para 7 milhões de alunos; no mesmo período a rede pública cresceu $74 \%$.

Destacamos, neste texto, algumas das políticas que contribuíram para essa expansão, mesmo que algumas delas tenham incentivado o crescimento pela via de instituições privadas. $\bigcirc$ Programa Universidade para Todos, que ficou conhecido como Prouni (BRASIL, 2005), é um programa do Ministério da Educação, criado em 2004, que concede bolsas de estudos integrais e parciais, em instituições privadas de ensino superior, que disponibilizam as vagas em troca da isenção de alguns impostos. 
As políticas de formação de professores: a expansão comprometida

Outra legislação desse período que contribuiu para a expansão foi - Decreto n 5.622, de 19 de dezembro 2005 (BRASIL, 2005a) que regulamenta a educação a distância, colocando-a como modalidade educacional que ocorre com a utilização de tecnologias de informação e comunicação. Esse Decreto foi complementado por outro, de número 5.800, de 2006 (BRASIL, 2006), que criou o Sistema Universidade Aberta do Brasil (UAB), "[...] voltado para o desenvolvimento da modalidade de educação a distância, com a finalidade de expandir e interiorizar a oferta de cursos e programas de educação superior no País" (BRASIL, 2006, p. 1). Em 2012, a modalidade a distância já representava $15 \%$ das matrículas nos cursos de graduação.

A criação do Programa de Apoio a Planos de Reestruturação e Expansão das Universidades Federais - Reuni, por meio do Decreto n 0.096 , de 24 de abril de 2007 (BRASIL, 2007c), foi o estímulo dirigido às IFES, que, numa espécie de contrato de gestão, estabeleciam metas de crescimento relativo às matrículas e ao número de concluintes e em troca receberiam até $20 \%$ do orçamento para infraestrutura. No mesmo período, por meio do Decreto n 6.095, de 24 de abril de 2007 (BRASIL, 2007b), foram estabelecidas as diretrizes para o processo de integração de instituições federais de educação 46 tecnológica, para a constituição dos Institutos Federais de Educação, Ciência e Tecnologia. Em 2012, segundo o Censo da Educação Superior, os IFs já eram responsáveis por 13,5\% das matrículas.

Finalmente, para os objetivos deste texto, o Decreto n $n^{\circ}$ 6.755, de 29 de janeiro de 2009 (BRASIL, 2009) instituiu a Política Nacional de Formação de Profissionais do Magistério da Educação Básica e a Portaria do MEC n 9 do mesmo ano cria o Parfor, um programa para a formação presencial e a distância de professores em exercício (BRASIL, 2009a).

Neste texto, abordaremos a expansão da educação superior por meio dos cursos de formação de professores, buscando evidenciar se houve um crescimento de matrículas, seja na formação inicial ou continuada, presencial e a distância e também nos Institutos Federais que ofertam essa etapa de ensino.

$\bigcirc$ objetivo é realizar uma análise dessas políticas de expansão, com ênfase na formação, procurando identificar o crescimento, levando em conta a categoria administrativa (público e privado) e a organização acadêmica/ arquitetura acadêmica (universidade, centro universitário, faculdade e institutos federais). 


\section{Olgaíses Mavés | Stella Segenreich | Celia Otranto}

\section{A expansão dos cursos de formação de professores (presencial)}

A formação de professores ganhou, nos últimos 20 anos, um status de prioridade. Os índices de escolarização e de aprovação passaram a ser os motivos centrais para que os governos, nas diferentes esferas federativas, passassem a ter uma forte preocupação com a formação, na medida em que imputavam ao professor a responsabilidade pelo processo de ensino e aprendizagem. Ademais, com a implantação de políticas de avaliação, a partir dos anos 1990, se instalou uma política de responsabilização dos professores pelos resultados que os alunos obtêm nos exames externos e padronizados.

A Lei de Diretrizes e Bases da Educação Nacional, de 20 de dezembro de 1996 - LDBN - (BRASIL, 1996) dedicou um capítulo para os profissionais da educação, reforçando e dando base legal às ações necessárias para a implementação de políticas de formação.

conjunto de leis, já arroladas na Introdução deste texto, demonstra o interesse dos governantes em relação à ampliação de cursos em nível superior, para formar os profissionais necessários ao cumprimento dos compromissos assumidos pelo governo brasileiro em âmbito internacional, como é o caso da Conferência Mundial de Educação para Todos, realizada em 1990 na Tailândia, que, no Plano de Ação para Satisfazer as Necessidades Básicas de Aprendizagem, aprovado no âmbito da Declaração Mundial sobre Educação para Todos, elenca alguns pontos como fundamentais; dentre eles, destacam-se a universalização do acesso à educação básica com equidade, no afã de atender a milhares de crianças que não conseguiram ingressar nesse nível de ensino.

Ora, o atendimento a esse compromisso, firmado pelos governos signatários da Declaração, exige que se invista na formação de professores que possam atender a esses futuros alunos. No período de 2001 a 2012, referente à formação de professores, as universidades, foram responsáveis por mais da metade dos cursos ofertados. Contudo, quando desdobramos os dados, podemos identificar que esse crescimento não foi linear, ao contrário. No período de 2006 a 2009, o crescimento foi negativo nas Universidades, o mesmo ocorrendo nos Centros Universitários que indicaram uma diminuição dos cursos nesse período, sendo de 2006 a 2007 -0,83 e 2008 a $2009-0,20$. As Faculdades também apresentaram uma diminuição dos cursos, sendo - 0,23 nos anos de 2007 e 2008 e uma queda ainda maior no período de 2009 e 
As políticas de formação de professores: a expansão comprometida

2010, quando o número foi de -2,78. Apenas os Institutos Federais tiveram um crescimento no mesmo período, ainda que tímido, em função de sua recente criação, mas já em 2009-20 10 houve um crescimento de 8,03\%, mostrando o fôlego com o qual surgiv essa organização acadêmica.

Consideramos importante, para melhor entendimento, que se cruzem os dados da organização acadêmica, nos quais as Universidades indicam um maior aumento no número de cursos no período de 2001 a 2012, com a categoria administrativa desses. As instituições privadas tiveram um decréscimo $(-0,8)$ no mesmo período quando as Universidades, os Centros Universitários e as Faculdades apresentaram um dado negativo em relação aos Cursos de Formação, -0,4. Ou seja, houve um interregno de tempo (2006-20 10) no qual a Formação de Professores esteve em descenso (BRASIL, 2013).

A partir de 2007, temos uma série de medidas do governo federal que vão incrementar as políticas de formação de professores, o que pode ter concorrido para que, a partir de 2010, na rede pública e, sobretudo, nas Universidades esse quadro de decréscimo dos Cursos começasse a ser revertido. Dentre essas medidas, podemos destacar as seguintes: A implementação do Plano de Metas Compromisso Todos pela Educação - Decreto n 6.094 de 482007 - (BRASIL, 2007a), que, dentre as várias diretrizes estabelece aquelas (XII, XIII e XIV) referentes ao docente. O Decreto deixa clara a necessidade de instituir programa para formação inicial e continuada; implantar o plano de carreira, cargos e salários e valorizar o mérito do trabalhador da educação.

No ano de 2007, também foi instituído o Plano de Desenvolvimento da Educação (PDE), cujo objetivo foi amplamente divulgado, qual seja, melhorar a qualidade da educação no país, com foco prioritário na educação básica. Assim, a primeira ação do Plano refere-se à Educação Básica e neste a Formação de Professores e o Piso Salarial Nacional (BRASIL, 2007). Nesse item, a importância dessas ações é traduzida da seguinte maneira: "Um dos principais pontos do PDE é a formação de professores e a valorização dos profissionais da educação" (BRASIL, 2007, p. 12).

Também foi instituído, em 2007, o Fundo de Manutenção e Desenvolvimento da Educação Básica e da Valorização dos Profissionais da Educação - Fundeb (BRASIL, 2007d, p.) que, no artigo 22, autoriza que "[...] pelo menos $60 \%$ dos recursos anuais totais dos Fundos serão destinados 
ao pagamento da remuneração dos profissionais do magistério da educação básica [...]."

Podemos observar que as duas ações, de certa forma, se complementam, na medida em que a legislação aprovada dá uma espécie de garantia ao que é propugnado no PDE. Contudo, não percebemos, ainda, nos anos seguintes, os impactos esperados dessas políticas. Ao examinarmos a situação das matrículas nos Cursos de Formação, constatamos que, tanto nas Universidades, quanto nos Centros Acadêmicos essas políticas tiveram um crescimento negativo nesses anos. Apenas, os Institutos Federais, então recém-criados, iniciam esse período já com 1,5\% das matrículas, tendo crescido, desde então, sendo responsáveis, no ano de 2012 , por 7,8\% das matrículas nos cursos de formação.

Na verdade é o setor privado que apresenta um maior crescimento negativo no período de 2006-2007, menos 5,56\%, em relação às matrículas, seguido de um período de ascensão e novamente uma queda de menos 3,58. (MEC/INEP/DEED 2009-2010).

Não há, ainda, uma recuperação do número de cursos de formação, sequer do número de matrículas, malgrado as políticas já instituídas. Essa é uma situação mundial, a pouca atratividade exercida pelo magistério. A Organização para a Cooperação e o Desenvolvimento Econômico (OCDE) tem desenvolvido pesquisas sobre a questão da formação de professores, tendo, em 2006, publicado o Relatório: "Professores são importantes: atraindo, desenvolvendo e retendo professores eficazes (2006)" sobre uma pesquisa, que teve como objetivo examinar alguns dos obstáculos para evitar a "escassez" de professores.

Um dos pontos elencados pela OCDE é a necessidade de tornar a docência como uma opção de carreira atraente. Para tanto, alguns pontos são elencados como fundamentais, como, por exemplo, a valorização da profissão que pode ocorrer, dentre outras variáveis, pela equiparação do salário com outras profissões que exigem o mesmo nível de escolaridade; pela existência de uma carreira que aponte a possibilidade de crescimento profissional e salarial ao longo do tempo; por uma formação inicial que desperte no estudante o interesse para seguir a profissão e cursos de formação continuada que possam contribuir para melhor desempenho do professor e, consequentemente, maiores oportunidades de crescimento na carreira. 
As políticas de formação de professores: a expansão comprometida

Parece que o Brasil vem fazendo a lição de casa, pelo menos, em nível de legislação. Em um artigo de 2012, Mavés e Camargo analisam algumas das legislações em curso relativas à valorização dos professores. As autoras citam, dentre outras, a Lei do Piso Salarial, n 11.738 , de 16 de julho de 2008, (BRASIL, 2008) e a Lei que institui a Política Nacional de Formação de Professores, além da Portaria que cria o Parfor, programa voltado para qualificar, em nível superior, os professores da educação básica em exercício. Apesar da legislação existente, nem sempre essas são cumpridas. É o caso, por exemplo, do Piso Salarial, pois, apenas, O6 Estados cumprem-no integralmente.

A OCDE (2013) publicou os resultados de outra pesquisa Teachingand Learning International Survey (TALIS), que passou a ser conhecida no Brasil , por Pesquisa Internacional sobre Ensino e Aprendizagem cujo objetivo é obter dados sobre as escolas e as condições de trabalho dos professores. Em 2013, a OCDE apresentou os resultados, dos quais destacamos alguns que estão diretamente vinculados às questões de formação inicial e continuada de professores.

Um dos pontos salientados pelo relatório se refere à necessidade de 50 haver uma rede de apoio aos professores menos experientes. Ou seja, o professor já está em atuação e, mesmo tendo um curso superior, o que ocorre com cerca da metade dos professores que atua na educação básica, ele ainda não tem a experiência necessária para atuar. É aí que a pesquisa identifica que os cursos de formação continuada devem se voltar para permitir que os professores dominem as matérias que ensinam, tenham competências pedagógicas, conheçam o programa do Curso no qual trabalham, adquiram prática de avaliação dos alunos e saibam gerenciar as turmas, para evitar a indisciplina e o desperdício de tempo.

Outra investigação empírica, A Pesquisa Trabalho Docente na Educação Básica no Brasil (TDEB), realizada, a primeira fase em 2009-2010 que abrangeu 07 Estados, dentre eles, o Pará , teve como objetivo analisar a formação, o vínculo empregatício, o nível salarial, as condições de trabalho, a participação em sindicatos e partidos políticos dos professores, procurando subsidiar a elaboração de políticas públicas no país. Alguns dados coletados são importantes para uma melhor e maior compreensão dessa problemática relativa à expansão da educação superior via cursos de formação de professores. 
A valorização profissional é um dos elementos mais importantes na escolha de uma dada profissão. A formação inicial e continuada, o salário e o plano de carreira são alguns deles. Esses fatores são, na maioria das vezes, determinantes para a escolha do Curso a ser feito e, depois, para exercer a profissão para a qual a academia preparou. Na pesquisa citada, (TDEB) 73\% informam que desconhecem a existência de um Plano de Cargos e Salários .

As diferentes situações apresentadas nas pesquisas citadas $1 O C D E$, UFMG) podem servir como parâmetro para análise dos dados referentes ao número de cursos, que está em declínio, assim como as matrículas.

No que tange ao pico apresentado nos anos 2009-20 10 em relação aos Cursos e as Matrículas, levanta-se a hipótese de que o Plano Nacional de Formação de Professores (Parfor), que foi instituído em 2009 (BRASIL, 2009a), destinado aos professores em serviço, sem a formação específica em nível superior, esteja sendo o responsável por esse crescimento. São necessários mais elementos para que se possa fazer essa afirmação.

Caso se comprove essa hipótese, a situação é muito preocupante, pois o "aumento" de cursos e matrículas não está ocorrendo em função de os novos sujeitos estarem buscando os Cursos de Formação, mas sim, por meio de professores que já estão na ativa e que, em médio prazo, estarão se aposentando.

A questão, pois, está na eminência de se ter uma penúria de professores, caso essa situação não seja revertida, por meio de políticas agressivas que, de fato, possam atrair os jovens para os Cursos de Licenciatura.

\section{O espaço da EAD na expansão da educação superior brasileira e da formação de professores}

Desde sua inserção formal no sistema de educação superior, mediante o disposto no artigo 81 da Lei de Diretrizes e Bases da Educação Nacional, 20 de dezembro 1996, e marcos regulatório que a Educação a Distância (EaD) tem cumprido uma trajetória meteórica de expansão no sistema de educação superior. No período compreendido entre 1998 e 2005, a expansão da EaD nos cursos de graduação acontece, principalmente, na rede privada. A partir da sua regulamentação em 19 de dezembro de 2005, o governo federal passa a utilizar diretamente a rede pública de educação superior para 
As políticas de formação de professores: a expansão comprometida

atingir suas metas de expansão da educação superior, Sobressaindo a formação de professores pelo Sistema Universidade Aberta do Brasil, no que se refere à educação a distância.

Entre 1998 e 2012, 276 instituições de ensino superior (IES) solicitaram e obtiveram credenciamento para ministrar cursos na modalidade EAD nos níveis de graduação e/ou de pós-graduação. De 1.682 estudantes matriculados em cursos de graduação a distância, registrados no primeiro Censo da Educação Superior (2000) incluindo dados sobre EAD, esse total chegou a 1. 1 13.850 no Censo de 2012. De uma presença de 0,06\% no total de matrículas nos cursos de graduação em 2000, esse percentual subiu para 15,8\% em 2012 . Seguindo o mesmo raciocínio em relação a esses cursos na área da Educação (Pedagogia e cursos de formação de professores), verificamos que os mesmos 1.682 estudantes registrados em 2000, todos da área da educação, representavam 0,29\% dos cursos em 2000. Esse percentual subiu para $32,9 \%$ em 2012, representando um contingente significativo.

Uma análise dos dados quantitativos referentes ao período 2001 2012 , a exemplo do que foi feito em relação à formação presencial, poderia trazer importantes subsídios para reler questões que vêm sendo postas pela

52 comunidade acadêmica no que se refere à educação a distância e à formação de professores. Segundo Gatti (2004, p. 13), "[...] há problemas educacionais que para sua contextualização e compreensão necessitam ser qualificados através de dados quantitativos."

Entretanto, os dados disponibilizados nas sinopses do Censo da Educação Superior, disponibilizadas pelo Inep (BRASIL, 2012), apresentam lacunas e flutuações de registro que têm impedido de se proceder a uma análise sistemática da trajetória da educação a distância no Brasil tanto no que se refere aos cursos de graduação a distância como, mais ainda, no que tange à formação de professores. As estatísticas da distribuição dos cursos por área de conhecimento, por exemplo, só começaram a constar das sinopses a partir de 2009.

Por outro lado, a utilização dos totais de curso ficou prejudicada pelo seu critério de registro. Nas duas primeiras sinopses (2000 e 2001), os cursos não eram contabilizados explicitamente. A partir de 2002, o Inep passou a totalizar o número de cursos abarcando sua oferta nos diferentes polos. A Universidade Federal de Santa Catarina, por exemplo, ofereceu cinco cursos 
na área de Educação - formação específica - mas são registrados sete cursos porque um deles é oferecido em três polos. Optamos, então, por utilizar o número de matrículas como base de dados por ser o dado mais estável para representar as estatísticas e, tomou-se como base, em alguns momentos, os dados gerais da EAD.

Mesmo em relação às estatísticas referentes ao total de matrículas, é importante fazermos uma ressalva sobre sua alocação nas diferentes regiões do Brasil. Nas primeiras sinopses, as matrículas eram distribuídas pelos polos, o que retrata uma das especificidades da educação a distância que, segundo a definição de Litwin (200 1), trata-se de uma nova proposta, na qual os docentes ensinam e os alunos aprendem mediante situações não convencionais, ou seja, em espaços e tempos não compartilhados.

Entretanto, esse registro não representa a especificidade do modelo brasileiro de educação a distância no que se relaciona à possibilidade de oferta de cursos em polos não sediados na sede da instituição, ao contabilizar a matrícula de todos os polos na instituição sede. A única pista nas sinopses para essa distorção foi encontrada na sinopse de 2002 na qual a Universidade Federal de Santa Catarina registra a existência de 4 polos em Salvador (Bahia) com 398 estudantes da Região Nordeste. Assim, em um estudo realizado sobre a presença da EAD no Prouni (SEGENREICH, 2009) foi feito um levantamento, no site de inscrição dos candidatos, das instituições que ofereciam bolsas assim como o número e localização dos polos na Região Norte e Nordeste. Somente a Universidade Norte do Paraná, IES sediada em Londrina, oferecia bolsas em 22 polos da Região Norte e 68 da Região Nordeste, em 2008. Entretanto, os alunos desses polos figuravam nas matrículas da Região Sul. Apesar de não contarmos com dados primários, as observações feitas sobre a distribuição geográfica da EAD, como um todo, são plenamente aplicáveis aos cursos de formação de professores. Não existem dados disponíveis nas sinopses e relatórios técnicos que permitam avaliar a real distribuição de matrículas nos cursos de formação de professores nas diferentes regiões do país.

Finalmente, reconhecendo que os mais recentes marcos regulatórios caminham pari passu com as estratégias de expansão da educação superior via $E A D$, eles servirão de fio condutor para interpretar os dados quantitativos apresentados. Seguindo o ciclo de formulação de políticas públicas, formulado por KIngdon (2006), serão levadas em consideração: a inclusão da EAD na 
As políticas de formação de professores: a expansão comprometida

agenda das políticas de expansão, mediante sua legitimação pela LDB / 1996 (BRASIL, 1996) e incentivo ao atendimento das necessidades de expansão (PNE 2001-2010); a construção do texto político que, pressionado pelas metas de expansão estabelecidas pelo PNE 2001-2010 e negociações internas de grupos de interesse, resultou na sua regulamentação mediante o Decreto n 5.622, de 2005 (BRASIL, 2005a); as ações diretas do governo federal, no seu âmbito de atuação, como a Universidade Aberta do Brasil, criada, oficialmente, em 2006 para implementação da decisão de expandir a educação superior via EAD no sistema público.

\section{Expansão/privatização da EAD no sistema de Educação Superior}

As categorias expansão e privatização caminham lado a lado no que relaciona à evolução da matrícula nos cursos de graduação a distância. Concernente à expansão das matrículas, já foi constada, em estudos anteriores ISEGENREICH; CAMARGO; OTRANTO; CASTANHEIRA; MAUÉS, 2010), a explosão de matrículas no período 2001-2002, que se seguiu ao PNE, com um aumento de $659,7 \%$. Houve uma quebra dessa tendência nos índices de crescimento de 2002-2003 e 2003-2004, 22,6\% e 19,4\% respectivamente. ritmo acelerado de crescimento foi retomado a partir de 2004 sendo que, de 2007 a 2008, esse índice alcançou 96,9\%. A partir desse ano, o crescimento tem sido contínuo, mas de forma menos acelerada.

No que se refere à distribuição das matrículas entre a rede pública e a privada, verificamos o predomínio da rede pública no período 2001-2003. Em 2004, a iniciativa privada se faz significativamente presente a ponto de ultrapassar, já em 2005, a rede pública, com 52,4\% das matrículas. Em 2012, esse percentual de participação alcançou 83,7\%.

As sinopses estatísticas dos censos do Inep não apresentam nenhum dado por área até 2008, o que prejudica analisar a trajetória de expansão e privatização dos cursos de formação de professores. Pela leitura dos dados disponíveis no período 2009-2012, podemos constatar um crescimento contido desses cursos tanto no setor público como no privado. Entretanto, de 2011 para 2012, notamos um crescimento maior do setor privado, sendo que a maior concentração de matrículas - 75,2 e 75,6\% respectivamente - incide nos cursos de Pedagogia. Se considerarmos o total de matrículas de 2012 em 
cursos da área de Educação, incluindo os cursos de formação de professores, esse percentual cai para $63 \%$.

Conforme Segenreich (2014), entre 2000 e 2003, a predominância das matrículas de EAD, na área de Educação e na rede pública, se explica pela presença de iniciativas do governo estadual no sentido de certificar seus professores para atender às diretrizes da LDB/96 e metas do PNE 2001 . Em 2012, os cursos da área de Educação representavam 32,9\% das matriculas em EAD, tendo em vista que as IES privadas se voltaram, principalmente, para os cursos superiores de tecnologia, direcionadas que são para as necessidades do mercado. Consequentemente, o processo de privatização também é menos intenso nessa área de estudo, em comparação com o total de cursos em EAD. Em 2012, o percentual de cursos da rede privada nos cursos de Pedagogia e formação de professores é de $76 \%$, contra os $83,7 \%$ dos cursos de EAD em geral.

\section{A expansão das matrículas na área de educação, por organização acadêmica}

Considerando que esses dados somente foram contabilizados a partir de 2009, vamos nos apoiar, mais uma vez, em estudos anteriores e em uma comparação com os dados das EAD em geral e dos cursos de formação inicial de professores, já apresentados.

Acompanhando a trajetória das sinopses estatísticas, constatamos que, nos anos de 2000 e 2001 , as universidades federais e estaduais eram as únicas que ofereciam cursos a distância e todos na área de educação. Nesse período, foi criada uma nova arquitetura acadêmica na figura de consórcios de IES públicas, em parceria com secretarias de Educação para certificar professores nos estados de São Paulo (PEC), Minas Gerais (Veredas) e Rio de Janeiro (Cederi), que vão manter a participação da área pública alta. É um reflexo direto das novas diretrizes estabelecidas pela LDB/96 e das metas de qualificação estipuladas pelo PNE 2001-2010.

Os dados do censo de 2002 já registram a presença de matrículas nos centros universitários e faculdades e as matrículas crescem, rapidamente, a cada ano nesses dois tipos de organização. A partir de 2008, começam a ser registradas as matrículas nos Institutos Federais de Educação Ciência e 
As políticas de formação de professores: a expansão comprometida

Tecnologia (IFs) e Centros Federais de Educação Tecnológica (Cefets), como veremos a seguir, neste texto. Em 2012, não somente cresceu o número de instituições como também eles passaram a ser oferecidos em outras áreas e por todas as formas de organização acadêmica reconhecidas pelo MEC nos dados censitários sobre ensino superior.?

Entretanto, a falta de dados estatísticos das matrículas por área de conhecimento, no período 2007-2008, nos impediu de distinguir, desde seu nascedouro, os efeitos da criação da Universidade Aberta do Brasil (UAB), a ação governamental mais representativa da utilização da EAD para a expansão das matrículas para a formação de professores.

No quadro das estatísticas referentes à matrícula por área e organização acadêmica, destacamos a distribuição das matrículas nas universidades no período 2009-20 12, inclusive em relação às categorias público/privado, em função da presença da UAB. Constatamos que, nesse período de três anos, as universidades privadas tiveram um decréscimo de matrículas em cursos da área de educação entre 2009 e 2010 retomando seu crescimento a partir de 2010, com concentração, principalmente, nos cursos de Pedagogia.

Quanto às universidades públicas, não há registro do seu ritmo de crescimento de matrículas no início da implantação da UAB; o que observamos, nos dados das sinopses estatísticas, é um lento aumento no período 2009-2012. Em um levantamento de dados feito no site da UAB/CAPES (SEGENREICH, 2014) constatamos que, dos 735 cursos oferecidos em 2013 pelo Sistema UAB, somente cerca de 50\% (335) eram de licenciatura. Os cursos de aperfeiçoamento e especialização já somavam um total de 319. Quanto às matrículas de cursos de aperfeiçoamento e especialização, não há dados censitários tampouco sobre a rede pública nem sobre a rede privada.

Outro ponto que merece destaque, na análise dos dados quantitativos sobre a distribuição das matrículas por organização acadêmica, é que elas se fixam em um conjunto de arranjos organizacionais que não contemplam as novas arquiteturas acadêmicas. As novas arquiteturas acadêmicas na área pública como os consórcios, por exemplo, não são retratadas nem nas estatísticas do período 2001-2003 nem no que se refere à Universidade Aberta do Brasil. A partir do que já foi estabelecido em trabalho anterior deste eixo da pesquisa (SEGENREICH; MOROSINI; FRANCO, 2012) adotamos 
a concepção de que a educação a distância se apresenta como uma nova arquitetura acadêmica, no sentido de arquitetura pedagógica. Segundo essas autoras:

A arquitetura acadêmica pode assumir distintas conotações. Arquitetura institucional, arquitetura organizacional, arquitetura pedagógica são expressões usadas para designar dado tipo de estruturação que protagoniza a educação, seja institucional e/ou modalidade de ensino [...] (SEGENREICH; MOROSINI; FRANCO, 2012, p. 76).

Considerada neste texto como uma nova arquitetura pedagógica, legitimada legalmente e inserida oficialmente no sistema educacional, a partir de 1996, a EAD leva a alterações nas arquiteturas organizacionais das instituições ou são plenamente utilizadas nas transformações do sistema de ensino superior. No setor privado, as fusões de grandes instituições, e a incorporação de faculdades de pequeno e médio porte a essas "grandes" instituições é notícia em revistas especializadas em assuntos econômicos, mas não tem sua contrapartida em dados da área educacional. Estamos diante de grandes mudanças na configuração do sistema de educação superior sem que o MEC tenha capacidade de registrá-la. Até que ponto essas mudanças têm repercussão na formação de professores? É uma questão extremamente pertinente.

\section{Instituto Federal de Educação, Ciência e Tecnologia: novo 'lócus' de formação de professores?}

Os Institutos Federais de Educação Ciência e Tecnologia (IFs) são instituições públicas federais que ocupam lugar de destaque na política de expansão da educação superior do governo Lula da Silva, no campo da educação profissional. Foram criados com base na agregação de instituições de educação profissional, já existentes no sistema federal: 33 Centros Federais de Educação Tecnológica (Cefets): 39 Escolas Agrotécnicas Federais (EAFs), 32 Escolas Vinculadas às Universidades Federais (EVs) e 7 Escolas Técnicas Federais (ETF). Na época, passaram a integrar os IFs a totalidade das EAFs (39), 31 CEFETs e 8 EAVs e 7 ETF. 
As políticas de formação de professores: a expansão comprometida

A forma como foram instituídos, unindo instituições já existentes, para formar uma nova organização acadêmica, com estrutura administrativa, objetivos e abrangências diversas das que thes deram origem, permite atribuir-thes a caracterização de uma nova arquitetura acadêmica.

Para definir mais claramente como a expansão da educação superior e da formação de professores está se dando por essa via, é necessário caracterizar melhor essa nova arquitetura acadêmica denominada Instituto Federal, que trataremos pela sigla IF.

Os Institutos Federais foram criados pela Lei n 11.892, de 29 de dezembro de 2008 (BRASIL, 2008a), que também instituiu a nova Rede Federal de Educação Profissional, composta pela Universidade Tecnológica do Paraná, 38 Institutos Federais, 2 Cefets e 24 Escolas Vinculadas às Universidades Federais que não aderiram à proposta governamental de integração aos IFs. Posteriormente, no ano de 2012 , a partir da Lei n 12.677, o Colégio Pedro II passou a integrar a referida Rede (BRASIL, 2012).

A Rede Federal de Educação Profissional e a forma como foram criados os IFs, já foram analisadas em publicações anteriores de Celia Otranto (2010; 2012). Neste texto, nosso foco é o percurso político que culminou com a criação dessa nova arquitetura acadêmica e sua participação na expansão da educação superior e dos cursos de formação de professores. Levando em consideração que a criação dos Institutos Federais é recente (2008), procuramos fazer um recorte (2003-20 1 2) da macropolítica para a educação superior que vem sendo implantada no Brasil, nos últimos anos, a fim de fundamentar nossas análises. Elegemos o ano de 2003 como o marco inicial desse recorte, pelo fato de o presidente Lula da Silva ter instituído, nesse ano, pelo Decreto Presidencial de 20 de outubro de 2003 (BRASIL, 2003) um Grupo de Trabalho Interministerial (GTI) encarregado de analisar a situação da educação superior e apresentar plano de ação voltado à reestruturação, desenvolvimento e democratização das Instituições Federais de Ensino Superior - IFES.

Otranto (2006) defende a ideia de que o Relatório Final do GTI serviu de base às novas políticas de educação superior no país a partir de 2003. Toma como referência as reflexões contidas no Relatório a respeito de alguns indicadores de crise nesse nível de ensino e a proposição, no mesmo texto, de duas soluções para enfrentar a crise: a) um programa emergencial de apoio ao ensino superior, especialmente às universidades federais; b) uma 
reforma universitária mais profunda (BRASIL, 2003). A tese da pesquisadora citada acima pode ser ratificada em análises mais detalhadas das políticas implantadas pelo governo brasileiro. A título de ilustração, são apontados, neste texto, somente alguns exemplos. $\bigcirc$ "programa emergencial" se materializou no "Programa de Apoio a Planos de Reestruturação e Expansão das Universidades Federais - Reuni" pelo Decreto 6.096, de 24 de abril de 2007 (BRASIL, 2007c). A reforma "mais profunda" passou pela reposição do quadro docente, ampliação de vagas para estudantes, educação a distância, autonomia universitária e financiamento, cujas análises não fazem parte da temática do presente artigo.

No que diz respeito à Reforma da Educação Profissional, instituída a partir de 2008 na rede federal, podemos encontrar, incorporadas ao Relatório do GTI, algumas diretrizes do Banco Mundial (1994; 1999) que fundamentaram a política educacional de educação profissional, dentre as quais, destacamos: a) o incentivo à diversificação da educação superior; b) a criação de instituições de educação superior profissionais.

A indicação de substituir boa parte das universidades de pesquisa por universidades de formação profissional de quatro anos, institutos isolados e centros vocacionais e/ou de formação técnica, com duração de dois anos já constava no documento do Banco Mundial de 1999 (BANCO MUNDIAL, 1999). Quando foi incorporada ao relatório do GTI, abriu caminho para a criação dos Institutos Federais e para a transformação gradativa de instituições de ensino médio em instituições de educação superior, tomando como referência os Cefets.

Após a divulgação do Relatório do GTI, o governo federal foi pródigo em normatizar a educação profissional, com destaque para o ano de 2004, quando editou três decretos: Decreto n 5. 154, de 20 de julho de 2004 (BRASIL, 2004) regulamentando a oferta de educação tecnológica de graduação e articulação entre os ensinos médio e técnico; Decreto n 5.225 , de $1^{\circ}$ de outubro de 2004 (BRASIL, 2004a), elevando os Cefets, tradicionais escolas de ensino médio e técnico, a instituições de educação superior; Decreto $n^{\circ}$ 5.254, de $1^{\circ}$ de outubro de 2004 (BRASIL, 2004b), dispondo sobre a organização dos Cefets, que, na ocasião eram as principais escolas de educação profissional do país. Além disso, no mesmo ano, editou duas leis que ocasionaram reflexos imediatos na educação profissional: a Lei $n^{\circ} 10.973$, nº de 2 de dezembro de 2004 (BRASIL, 2004c), conhecida como Lei da Inovação 
As políticas de formação de professores: a expansão comprometida

Tecnológica, que "[...] dispôs sobre incentivos à inovação e à pesquisa científica e tecnológica [...]" e a Lei n 11.079 , de 30 de dezembro de 2004 (BRASIL, 2004d), que regulamentou as Parcerias Público-Privadas. $\bigcirc$ caminho estava, enfim, aberto para a Reforma da Educação Profissional pretendida pelo governo federal.

A ideia da criação de uma instituição diferente para toda a educação profissional federal, formada a partir da integração de instituições federais já existentes foi divulgada no ano de 2007 pelo Plano de Desenvolvimento da Educação (PDE) que defendeu a proposta dos Institutos Federais de Educação Ciência e Tecnologia. Segundo o PDE, os Institutos Federais deveriam oferecer "[...] educação profissional e tecnológica, como processo educativo e investigativo em todos os níveis e modalidades [...]" (BRASIL, 2007, p. 32).

Na mesma data de divulgação do PDE, 24 de abril de 2007, com o propósito declarado de estabelecer diretrizes para o processo de integração das instituições de educação profissional e tecnológica surgiu o Decreto $n^{\circ}$ 6.095 (BRASIL, 2007b), estabelecendo diretrizes sobre avaliação e supervisão das novas instituições que seriam criadas e, ainda, que elas seriam equiparadas às universidades, gozando, portanto, da mesma prerrogativa de 60 autonomia didático-científica e de gestão financeira e patrimonial. Outro ponto a ser destacado diz respeito à determinação de que os Institutos Federais deveriam aplicar o mínimo de vinte por cento de sua dotação orçamentária anual no oferecimento de cursos de licenciatura.

Quando a Lei $n^{\circ} 11.892$ foi homologada, em 29 de dezembro de 2008 (BRASIL, 2008a), as bases para a criação da Rede Federal e dos Institutos Federais de Educação, Ciência e Tecnologia já tinham sido determinadas por decreto, entretanto, os vinte por cento da dotação orçamentária para a implantação das licenciaturas se transformou em vinte por cento das vagas dos IFs destinadas à formação de professores, sem referência aos recursos para esse fim. Os IFs surgiram, então, como instituições repletas de atribuições, superior em quantidade a todas as demais existentes no Brasil.

Os Institutos Federais são "[...] instituições de educação superior, básica e profissional, pluricurriculares e multicampi, especializadas na oferta de educação profissional e tecnológica, nas diferentes modalidades de ensino." Equiparadas às universidades federais, atuam como "[...] instituições acreditadoras e certificadoras de competências profissionais [...]", com autonomia 
para criar e extinguir cursos, em sua área de atuação territorial, bem como para registrar diplomas dos cursos oferecidos (BRASIL, 2008a, p. 1).

$\bigcirc$ artigo $6^{\circ}$ da Lei $n^{\circ} 11$.892, de 29 de dezembro de 2008 (BRASIL, 2008a, p. 1 ) explicita as nove finalidades e características dos IFs, dentre as quais destacamos as mais significativas para o presente estudo: promover a integração e verticalização da educação básica à educação profissional e educação superior, otimizando a infraestrutura física, os quadros de pessoal e os recursos de gestão (art. $6^{\circ}$, inciso II), e qualificar-se como centro de referência no apoio à oferta do ensino de ciências nas instituições públicas de ensino, oferecendo capacitação técnica e atualização pedagógica aos docentes das redes públicas de ensino (art. $6^{\circ}$, inciso VII).

Para atender a essa última finalidade, a Lei $n^{\circ} 11.892$ de 2008 (BRASIL, 2008a), em seu artigo $8^{\circ}$ determina que 20\% da totalidade das vagas dos IFs devem ser destinadas à formação de professores. Para avaliar o que isso pode significar, recorremos aos Microdados do Censo da Educação Superior (BRASIL; MEC; INEP, 2012 ).

Ao analisarmos os dados da expansão as educação superior (cursos de graduação) na Rede Federal de Ensino, que integram o Censo da Educação Superior, constatamos que levam em consideração sempre os Cefets e os Institutos Federais, em conjunto. Consideramos importante destacar que, até o ano de 2008, contávamos com 33 Cefets e, a partir de 2008, restaram somente os dois que não aderiram à proposta governamental - Cefet Rio de Janeiro e Cefet Minas Gerais. Como nos dados do Inep, as instituições estão agrupadas (Cefets e IFs) e algumas análises podem ser prejudicadas se não atentarmos para essa especificidade.

Quanto à evolução no número de matrículas nos cursos de graduação presenciais, nos Cefets e nos IFs, no ano de 2003, contávamos com 33.801 matriculados; em 2009, primeiro ano de criação dos IFs, já eram 54.733 matrículas; e, em de 2012, ano do término dos registros do Censo, foram contabilizadas 97.939 alunos matriculados. Cabe-nos destacar, a partir da análise dos dados, que a expansão, no período de 2003 a 2012 foi de 64. 138 matrículas, ou seja, de 289,75\% (BRASIL; MEC; INEP, 2012).

No que tange aos cursos de graduação a distância, os primeiros dados estão relacionados ao ano de 2008, já que não existiam cursos a distância nos Cefets anteriormente a essa data. Em 2008, eram 3.092 matrículas; 
As políticas de formação de professores: a expansão comprometida

em 2009, 13.364 alunos matriculados; e em 2012, um pouco mais, 13.700 matrículas. Vale mencionar que houve um aumento, no ano de 2010, 118.934 matrículas), que começou a diminuir em 2011 (18.609 matrículas) até alcançar as 13.700, no ano de 2012 . De qualquer forma, a expansão, a partir de 2003, até o ano de 2012, foi de 10.608 vagas, o que nos leva ao percentual de 443,07\% de ampliação de cursos de graduação a distância nos IFs e nos Cefets (BRASIL, 2012).

No caso específico das licenciaturas, em 2003 contávamos com 4078 alunos inscritos, na sua quase totalidade nos Cefets, que ofereciam cursos de formação de professores para as disciplinas profissionalizantes. Entretanto, no ano de 2009, quando os IFs passaram a funcionar e a oferecer cursos de formação de professores para a educação básica, iá eram 10.630 matrículas e, no ano de 2012, os dados do Inep contabilizam 30.551 matrícula nos cursos de licenciatura presenciais, nos Cefets e nos IFs. Destacamos aqui o impressionante crescimento de 749,16\% (BRASIL, 2012), dos cursos de formação docente na Rede Federal que, considerando a existência atual de somente dois Cefets, podemos afirmar que a quase totalidade das licenciaturas, hoje, se encontra nos IFs.

62 Analisando os dados do Inep de 2012, constatamos que a região Nordeste foi a que mais cresceu no quadro da evolução de matrículas, chegando em 2012 a 11.507 alunos matriculados, dentre os 30.551 de todo território nacional (BRASIL, 2012). Os dados também apontam para uma redução da oferta de cursos tecnológicos, na mesma proporção em que aumenta a oferta dos cursos de licenciatura, em todas as regiões do país. Percebemos, também, um incentivo governamental mais evidente na expansão dos cursos de formação de professores do que na oferta de cursos tecnológicos.

Com a implantação dos IFs, o número de cursos de licenciatura foi ampliado consideravelmente. É o que comprova a pesquisa realizada no ano de 2012, por Fernanda Lima (2013). Ela constatou que 60\% dos cursos de licenciatura que estavam sendo oferecidos, na época, pelos IFs tinham sido criados depois da Lei n 11.892 de 2008, que instituiu os Institutos Federais; $31 \%$ já existiam antes da Lei; e, em $9 \%$ dos cursos, a pesquisadora não conseguiu identificar a data de início da oferta. Computando todas as licenciaturas oferecidas pelos IFs em 2012, a mesma pesquisadora informou que 88\% eram direcionados à educação básica (290 cursos) e 12\% (39 cursos) à educação profissional (LIMA, 2013). O estudo demonstra que a maioria das licenciaturas 
está voltada, agora, para formar professores da educação básica, rompendo com a tradição de formação de quadros para a educação profissional e desconsiderando as necessidades de formar professores para as disciplinas profissionalizantes, geradas pela expansão dessa modalidade de ensino.

Lima comprovou, também, que a maioria dos cursos era oferecida, predominantemente, na Região Nordeste, no horário noturno, para as áreas de ciências e da matemática, de forma presencial. Somente 14 cursos de licenciatura nos IFs, 4\% do total, estavam sendo desenvolvidos na modalidade a distância (LIMA, 2013).

incentivo à formação de professores na Rede Profissional está evidenciado em vários documentos publicados pelo Ministério da Educação. No caso dos IFs, foi defendida antes mesmo dessas Instituições terem sido criadas, como apontam Antonio Ruiz, Mozart Ramos e Murílio Hingel, em 2007, no documento intitulado Escassez de professores no ensino médio; propostas estruturais e emergenciais. Os autores alertam para a carência de professores para o ensino médio, principalmente nas disciplinas da área de exatas e recomendam que os IFs deveriam suprir essa carência, tanto na formação inicial como na continuada (RUIZ; RAMOS; HINGEL, 2007).

No entanto, ressaltamos que estamos falando em formação de professores para a educação básica, em instituições que não têm tradição tampouco pesquisas na área e que, em muitos casos, não contam com professores licenciados para ministrar as disciplinas pedagógicas.

A pouca experiência com formação docente na rede federal profissional se iniciou com a criação dos primeiros Cefets (Rio de Janeiro, Minas Gerais e Paraná), provenientes da transformação das Escolas Técnicas Federais (ETF), no ano de 1978 (BRASIL, 1978). Estávamos, na época, em plena vigência da Lei n 5.692, de 1971 (BRASIL, 1971), instituída pela Ditadura Militar brasileira, que, dentre outras medidas, transformou os antigos cursos - primário e ginasial - em primeiro grau, e o nível médio, em segundo grau, determinando,ainda, a obrigatoriedade da integração entre os ensinos propedêutico e profissional. Os recém-criados Cefets passaram a oferecer licenciaturas plenas e curtas para suprir a carência de docentes no segundo grau e para a formação de tecnólogos (BRASIL, 1978, art. 2\%). Como as licenciaturas plenas eram demoradas e mais dispendiosas e havia necessidade urgente de docentes, no ano 1981, teve início a oferta dos chamados Esquemas I e II, voltados para a formação 
As políticas de formação de professores: a expansão comprometida

de professores de disciplinas especializadas do segundo grau, dando origem às licenciaturas de formação especial, também conhecidos como "cursos emergenciais."

Em 1993, a Lei n 8.711, de 28 de setembro de 1993, que transformou a Escola Técnica Federal da Bahia em Cefet, instituiu que a formação de professores, nessas instituições, passaria a ser direcionada, exclusivamente, para formar "[...] professores especializados para as disciplinas específicas do ensino técnico e tecnológico" (BRASIL, 1993, art. 3\%. Nesse sentido, a formação passou a ser restrita aos professores das disciplinas dos cursos profissionais. No ano 2000, porém, o Decreto $n^{\circ} 3.462$, de 17 de maio de 2000, (BRASIL, 2000) concedeu autonomia aos Cefets para criar cursos de formação de professores voltados para as disciplinas científicas e tecnológicas do ensino médio e da Educação Profissional. A partir dessa data, novos cursos de licenciatura foram implantados. No entanto, destacamos que eram poucos cursos e bem diferentes dos oferecidos pelas universidades federais, quer pela falta de quadros especializados, quer pela carência de pesquisas no campo da formação docente.

Os Institutos Federais são, em última análise, um novo lócus de for-

64 mação docente e, como tal, precisam firmar um compromisso educacional respeitoso com essa formação. Esse respeito será ampliado na mesma medida em que ampliarem os conhecimentos do campo da formação de professores dentro da complexa área das ciências humanas

\section{Considerações finais}

Algumas conclusões a que podemos chegar é que as políticas públicas de formação de professores em instituições com tradição nessa área não estão sendo suficientes para aumentar o interesse dos jovens acerca da escolha profissional direcionada para o magistério. Por esse motivo, está havendo um grande incentivo governamental no oferecimento das licenciaturas nos Institutos Federais, o que está ampliando, significativamente, essa oferta, na tentativa de evitar uma carência já anunciada. A preocupação tem sido recorrente, a ponto da OCDE (2006), no documento citado "Professores são importantes" fazer algumas recomendações com base na pesquisa realizada. A primeira delas diz respeito à necessidade de tornar a profissão competitiva salarialmente, 
capaz de atrair pessoas talentosas que veem a possibilidade de crescimento e realização profissional. Mas, é preciso também manter esses professores e, para tanto, uma carreira promissora pode ser a chave dessa etapa que está ligada à formação continuada, inclusive com liberação de carga horária para realizar cursos de mestrado e doutorado.

Importante que os governos, em nível federal e em níveis estaduais e municipais assumam a questão da formação de professores como uma questão fundamental no processo de desenvolvimento da educação, reconhecendo que o processo de ensino-aprendizagem terá resultados satisfatórios na medida em que, dentre os fatores intervenientes, tenha um quadro docente que esteja satisfeito com a profissão e que se sinta motivado no exercício cotidiano de seu trabalho.

Onsino presencial para a formação inicial é a demanda de entidades acadêmicas e científicas que não descartam o papel e a importância da educação a distância para a formação continuada, indicando a necessidade de cursos presenciais nessa etapa da educação. Ademais, o estudo, demonstra o crescimento na oferta das licenciaturas nos Institutos Federais, o que nos leva às reflexões se a falta de tradição e de pesquisas neste campo no interior dessas instituições, não poderia comprometer a qualidade da formação. Por outro lado, constatamos que as instituições tradicionais na oferta de cursos de formação docente - como, por exemplo, as universidades, centros universitários e faculdades de educação - não estão atraindo alunos em número suficiente para as licenciaturas e que, nesse sentido, os Institutos Federais poderiam ser uma alternativa. São muitas as indagações que subsidiarão a continuidade de nossas pesquisas. Esperamos que as políticas educacionais em vigor possam atentar para alguma das questões levantadas neste texto, as quais servirão de alerta não somente para a quantidade, mas também para a qualidade, uma vez que dela depende, dentre outras variáveis, que o país tenha uma educação transformadora.

\section{Notas}

1 Esses dados se referem aos países em desenvolvimento, como o Brasil.

2 Esse Decreto foi alterado pelo Decreto $n^{\circ} 2.306$ de 1997, posteriormente pelo Decreto $n^{\circ} 3.860$ de 2001 e pelo Decreto n 5.773 de 2006. 
As políticas de formação de professores: a expansão comprometida

3 A renúncia fiscal referente a quatro impostos ao não recolhimento de quatro impostos e contribuições federais (IRPJ, CSLL, PIS e COFINS. Em 2012, o país deixou de recolher R\$733,9 milhões referentes ao não recolhimento desses impostos.

$4 \quad$ Lei n 9.394 de 1996, no artigo 6.

5 No período de 2006 a 2007, o crescimento foi de - 0,45; nos anos de 2007-2008 foi de $-0,24$ e de 2008 a 2009 foi de - 0,12.

6 Brasil participou da pesquisa e o Inep foi o responsável pelo seu desenvolvimento.

$7 \quad$ Esta fase se constituiu de um surveycom 85 questões, tendo sido aplicada a mais de 9 mil sujeitos docentes. No estado do Pará participaram 1350 docentes.

8 A pesquisa foi coordenada pelas professoras Dalila Oliveira e Lívia Vieira da UFMG e envolveu os estados do Rio Grande do Norte, Goiás, Espírito Santo, Minas Gerais, Paraná, Santa Catariana e Pará, tendo a coordenação desse último sido da professora Olgaíses Mavés.

9 Plano de Carreira Cargos e Salários do estado do Pará foi aprovado em 2010.

10 Fontes: Sinopses Censos da Educação Superior do INEP 2000 - 2012; catálogo UAB/CAPES 2013/2014; a relação dos pareceres do Conselho Nacional de Educação 1998 - 2012.

11 Definimos o ano de 2009 como o primeiro a contabilizar os IFs, em virtude da Lei n 11.892 de 2008, que os criou, datar de 29 de dezembro de 2008, com publicação no Diário Oficial da União em 30 de dezembro de 2008. Consideramos, então, que o primeiro ano de funcionamento dos IFs foi 2009.

$12 \bigcirc$ Esquema I tinha por objetivo oferecer a formação pedagógica aos portadores de diploma de curso superior (bacharelado) que quisessem dar aulas. O Esquema II oferecia formação pedagógica aos portadores de diploma técnico que tivessem o mesmo propósito, além de ampliar conhecimentos relacionados às disciplinas específicas de conteúdo técnico. Os dois davam direito a lecionar no $2^{\circ}$ grau.

\section{Referências}

BANCO MUNDIAL. La enseñanza superior: las lecciones derivadas de la experiencia. 1994. Disponível em: http://firgoa.usc.es/drupal/files/0 10-1344Sp.pdf. Acesso em: 10 set. 2010.

Documento estratégico do Banco Mundial. A educação na América Latina e Caribe. Washington: The World Bank Group. 1999. Disponível em: http://www.bancomundial.org.br. Acesso em: 11 jul. 2014.

BRASIL. Lei n 5.692, de 11 de agosto de 1971. Fixa diretrizes e bases para o ensino de $1^{\circ}$ e $2^{\circ}$ graus e dá outras providências. Diário Oficial [da] República Federativa do Brasil, Poder Executivo, Brasília, DF, 12 ago. 1971, Seção 1, p. 6377. 
Lei n 6.545, de 30 de Junho de 1978. Dispõe sobre a transformação das Escolas Técnicas Federais de Minas Gerais, do Paraná e Celso Suckow da Fonseca em Centros Federais de Educação Tecnológica e dá outras providências. Diário Oficial [da] República Federativa do Brasil, Poder Executivo, Brasília, DF, 4 jul. 1978, Seção 1, p. 10.233.

Lei $n^{0} 8.711$, de 28 de setembro de 1993. Dispõe sobre a transformação da Escola Técnica Federal da Bahia em Centro Federal de Educação Tecnológica e dá outras providências. Diário Oficial [da] República Federativa do Brasil, Poder Executivo, Brasília, DF, 29 set. 1993, Seção 1, p. 14533.

Lei n 9.394, de 20 de dezembro de 1996. Estabelece as Diretrizes e Bases da Educação Nacional. Diário Oficial [da] República Federativa do Brasil, Poder Executivo, Brasília, DF, 23 dez. 1996, Seção 1, p. 27.833.

Decreto $n^{\circ} 2.207$, de 15 de abril de 1997. Regulamenta, para o Sistema Federal de Ensino, as disposições contidas nos arts. 19, 20, 45, 46 e $\S 1^{\circ}$, 52, parágrafo único, 54 e 88 da Lei n 9.394, de 20 de dezembro de 1996, e dá outras providências. Diário Oficial [da] República Federativa do Brasil, Poder Executivo, Brasília, DF. 16 abr. 1997. Disponível em: http://www. planalto.gov.br/ccivil_03/decreto/D2207.htm. Acesso em: 8 jan. 2010.

Decreto $n^{\circ} 3.462$, de 17 de maio de 2000. Dá nova redação ao art. $8^{\circ}$ do Decreto $n^{\circ} 2.406$, de 27 de novembro de 1997, que regulamenta a Lei n 8.948 , de 8 de dezembro de 1994. Diário Oficial [da] República Federativa do Brasil, Poder Executivo, Brasília, DF, 18 maio. 2000, Seção 1, p. 1.

Lei n ${ }^{\circ}$ 10.172, de 9 de janeiro de 200 1. Aprova o Plano Nacional de Educação e dá outras providências. Diário Oficial [da] República Federativa do Brasil, Poder Executivo, Brasília, DF, 10 jan. 2001. Disponível em: http://www.planalto.gov.br/ccivil_03/leis/ leis_2001/110172.htm. Acesso em: 8 ago. 2014.

Decreto Presidencial de 20 de outubro de 2003. Institui o Grupo de Trabalho Interministerial encarregado de analisar a situação atual e apresentar plano de ação visando a reestruturação, desenvolvimento e democratização das Instituições Federais de Educação Superior - IFES. Diário Oficial [da] República Federativa do Brasil, Poder Executivo, Brasília, DF, 21 out. 2003, Seção 1, p. 3.

Decreto $n^{\circ}$ 5.154, de 23 de julho de 2004. Regulamenta o $\S 2^{\circ}$ do art. 36 e os arts. 39 a 41 , da Lei n 9.394, de 20 de dezembro de 1996, que estabelece as diretrizes e bases da educação nacional, e dá outras providências. Diário Oficial [da] República Federativa do Brasil, Poder Executivo. Brasília, DF, 26 jul. 2004, Seção 1, p. 18. 
As políticas de formação de professores: a expansão comprometida

Decreto $n^{\circ}$ 5.225, de $1^{\circ}$ de outubro de 2004. Altera dispositivos do Decreto $n^{\circ}$ 3.860 , de 9 de julho de 2001, que dispõe sobre a organização do ensino superior e a avaliação de cursos e instituições, e dá outras providências. Diário Oficial [da] República Federativa do Brasil, Poder Executivo. Brasília, DF, 4 out. 2004a, Seção 1, p. 5.

Decreto $n^{\circ} 5.254$, de $1^{\circ}$ de outubro de 2004. Dispõe sobre a organização dos Centros Federais de Educação Tecnológica e dá outras providências. Diário Oficial [da] República Federativa do Brasil, Poder Executivo. Brasília, DF, 4 out. 2004b, Seção 1, p. 3.

Lei n 10.973, de 2 de Dezembro de 2004. Lei de Inovação Tecnológica. Dispõe sobre incentivos à inovação e à pesquisa científica e tecnológica no ambiente produtivo e dá outras providências. Diário Oficial [da] República Federativa do Brasil, Poder Executivo. Brasília, DF, 3 dez. 2004c, Seção 1, p. 2.

Lei nº 11.079 , de 30 de dezembro de 2004. Institui normas gerais para licitação e contratação de parceria público-privada no âmbito da administração pública. Diário Oficial [da] República Federativa do Brasil, Poder Executivo. Brasília, DF, 31 dez. 2004d, Seção 1, p. 6.

Institui o Programa Universidade para Todos PROUNI, regula a atuação de entidades beneficentes de assistência social no ensino superior, altera a Lei n ${ }^{\circ} 10.891$ de 9 de 68 julho de 2004 e dá outras providências. Diário Oficial [da] República Federativa do Brasil Poder Executivo. Brasília, DF, 14 de jan. 2005. Disponível em: http://www. planalto.gov. br/ccivil_03/_ato20042006/2005/lei/L1 1096.htm. Acesso em: 8 ago. 2014.

Decreto $n^{\circ}$ 5.622, de 19 de dezembro de 2005. Regulamenta o art. 80 da Lei $n^{\circ}$ 9.394 de 20 de dezembro de 1996, que estabelece as diretrizes e bases da educação nacional. Diário Oficial [da] República Federativa do Brasil, Poder Executivo. Brasília, DF, 20 dez. 2005a. Disponível em: http://portal.mec.gov.br/seed/arquivos/pdf/dec_5622. pdf. Acesso em: 8 ago. 2014.

Decreto $n^{\circ} 5.800$ de 8 de junho de 2006. Dispõe sobre o Sistema Universidade Aberta do Brasil - UAB. Diário Oficial [da] República Federativa do Brasil, Poder Executivo. Brasília, DF, 9 jun. 2006. Disponível em: http://www. planalto.gov.br/ccivil_03/_ato20042006/2006/decreto/d5800.htm. Acesso em: 10 ago. 2014

Ministério da Educação. Plano de Desenvolvimento da Educação. Razões, princípios e programas. Brasília: MEC, 2007.

Decreto $n^{0} 6.094$ de 24 de abril de 2007. Dispõe sobre a implementação do Plano de Metas Compromisso Todos pela Educação, pela União Federal, em regime de colaboração com Municípios, Distrito Federal e Estados, e a participação das famílias e 
da comunidade mediante programas e ações de assistência técnica e financeira, visando a mobilização social pela melhoria de qualidade da educação básica. Diário Oficial [da] República Federativa do Brasil, Poder Executivo, Brasília, DF, 25 abr. 2007a. Disponível em: hitp://www. planalto.gov.br/ccivil_03/_ato2007-2010/2007/decreto/d6094.htm. Acesso em: 15 maio 2009.

Decreto n ${ }^{\circ}$ 6095, de 24 de abril de 2007. Estabelece diretrizes para o processo de integração de instituições federais de educação tecnológica, para fins de constituição dos Institutos Federais de Educação, Ciência e Tecnologia - IFET, no âmbito da Rede Federal de Educação Tecnológica. Diário Oficial [da] República Federativa do Brasil, Poder Executivo, Brasília, DF, 25 abr. 2007b, Seção 1, p. 6.

Decreto n 6.096, de 24 de abril de 2007. Institui o Programa de Apoio a Planos de Reestruturação e Expansão das Universidades Federais - REUNI. Diário Oficial [da] República Federativa do Brasil, Poder Executivo, Brasília, DF, 25 abr. 2007 c, Seção 1, p. 7.

Decreto n 11 1.494, de 20 de junho de 2007. Regulamenta o Fundo de Manutenção e Desenvolvimento da Educação Básica e da Valorização dos Profissionais da Educação FUNDEB, de que trata o art. 60 do Ato das Disposições Constitucionais Transitórias; altera a Lei $n^{\circ}$ 10.195, de 14 de fevereiro de 2001; revoga dispositivos das Leis n 9.424, de 24 de dezembro de 1996, 10.880, de 9 de junho de 2004, e 10.845, de 5 de março de 2004; e dá outras providências. Diário Oficial [da] República Federativa do Brasil, Poder Executivo. Brasilia, DF, 25 abr. 2007d. Disponível em: http://www. planalto.gov.br/ ccivil_03/_ato2007-2010/2007/lei/l1 1494.htm. Acesso em: 15 maio 2010.

Lei $n^{\circ} 11.738$, de 16 de julho de 2008. Regulamenta a alínea "e" do inciso III do caput do art. 60 do Ato das Disposições Constitucionais Transitórias, para instituir o piso salarial profissional nacional para os profissionais do magistério público da educação básica. Diário Oficial [da] República Federativa do Brasil, Poder Executivo. Brasília, DF, 17 jul. 2008. Disponível em: hitp://www.planalto.gov.br/ccivil_03/_ato2007-2010/2008/ lei/11 1738.htm. Acesso em: $10 \mathrm{dez} .2009$.

Congresso Nacional. Lei no 1 1.892, de 29 de dezembro de 2008. Institui a Rede Federal de Educação Profissional Científica e Tecnológica e dá outras providências. Diário Oficial [da] República Federativa do Brasil, Poder Executivo. Brasília, DF, 30 dez. 2008a, Seção 1, p. 1.

Decreto n 6.755, de 29 de janeiro de 2009. Institui a Política Nacional de formação de profissionais do magistério da Educação Básica, disciplina a atuação da Coordenação de Aperfeiçoamento de pessoal de Nível Superior-CAPES no fomento a 
As políticas de formação de professores: a expansão comprometida

programas de formação inicial e continuada, e dá outras providências. Diário Oficial [da] República Federativa do Brasil, Poder Executivo. Brasília, DF, 30 jan. 2009. Disponível em: http://www.planalto.gov.br/ccivil_03/_ato2007-2010/2009/decreto/d6755.htm. Acesso em: 10 dez. 2009.

MEC. Portaria Normativa n 9, de 30 de junho de 2009. Institui o Plano Nacional de Formação dos Professores da Educação Básica no âmbito do Ministério da Educação. Diário Oficial [da] República Federativa do Brasil, Poder Executivo. Brasília, DF, O 1 jul. 2009a. Disponível em: http: / / proeg.ufam.edu.br/attachments/196_portaria\%20MEC\%20 Normativa\%20n.\%209\%20de\%2030\%20de\%20junho\%20de\%202009\%20lnstitui\%20 o\%2OPARFOR.pdf. Acesso em: 10 ago. 2014.

Lei $n^{\circ}$ 12.677, de 25 de junho de 2012. Dispõe sobre a criação de cargos efetivos, cargos de direção e funções gratificadas no âmbito do Ministério da Educação, destinados às instituições federais de ensino; altera as Leis nos 8.168, de 16 de janeiro de 1991, 1 1.892, de 29 de dezembro de 2008, e 11.526, de 4 de outubro de 2007. Diário Oficial [da] República Federativa do Brasil, Poder Executivo, Brasília, DF, 25 jun. 2012 , Seção 1, p. 2.

Ministério da Educação. Instituto Nacional de Estudos e Pesquisas Educacionais

Anísio Teixeira. Microdados do censo da educação superior. 2012 . Disponível em: http:// portal.inep.gov.br/basica-levantamentos-acessar. Acesso em: 13 jun. 2013.

Censo da educação superior 2012. Disponível em: http://portal.inep.gov.br/ web/censo-da-educacao-superior. Acesso em: 10 fev. 2014.

GATTI, Bernardete. Estudos quantitativos em educação. Educação e Pesquisa, São Paulo, v. 30, p. 1 1-30, jan./abr. 2004.

LIMA, Fernanda Bartoly Gonçalvez. A formação de professores nos Institutos Federais: perfil de oferta. Revista EIXO, Brasília, v. 2, n. 1, p.83-105, jan./jun. 2013.

KINGDON, John Wells. Juntando as coisas. In: SARAVIA, Enrique; FERRAREZI, Elisabete (Org.). Políticas públicas: coletânea. Brasília: ENAP, 2006.

LITWIN, Edith. Das tradições à virtualidade. In: LITWIN, Edith (Org.). Educação a distância: temas para o debate de uma nova agenda educativa. Porto Alegre: Artmed, 2001.

MAUES, Olgaíses; CAMARGO, Arlete. Marcos regulatórios nas políticas de formação e valorização docente pós-LDB. Revista Educação em Questão, Natal, v. 42, n. 28, p. 149174, jan./abr. 2012. 
MÉSZÁROS, István. Para além do capital: rumo a uma teoria da transição. Tradução Paulo Cezar Castanheira, Sérgio Lessa. São Paulo: Editora BOITEMPO, 2002.

OCDE. Educational a glance 2013. Disponível em: http://www.oecd.org/edu/ eag2013\%20(eng)-FINAL\%2020\%20June\%202013.pdf. Acesso em: 10 jan. 2014.

Professores são importantes: atraindo, desenvolvendo e retendo professores eficazes. São Paulo: EditoraModerna, 2006.

TALIS 2013. Results: international perspective on teaching and learning. Disponível em: http://www.keepeek.com/Digital-Asset-Management/oecd/education/talis-2013results_9789264196261-en\#page 1. Acesso em: 10 ago. 2014.

OTRANTO, Celia Regina. Desvendando a política de educação superior do governo Lula. Universidade e Sociedade, Brasília, v. 16, n. 38, p. 19-29, jun. 2006.

Criação e implantação dos Institutos Federais de Educação, Ciência e Tecnologia IFETs. Revista Retta, Seropédica, v. 1, n. 1, p. 89-108, jan./jun. 2010.

A reforma da educação profissional no Brasil: marcos regulatórios e desafios. Revista Educação em Questão, Natal, v. 42, n. 28, p. 199-226, jan./abr. 2012.

RUIZ, Antonio; RAMOS, Mozart; HINGEL, Murílio. Escassez de professores no ensino médio: propostas estruturais e emergenciais. Brasília, DF: Ministério da Educação, mai. 2007. Disponível em: http://portal.mec.gov.br/cne/arquivos/pdf/escassezl.pdf. Acesso em: 9 jul. 2014.

SEGENREICH, Stella Cecília Duarte. ProUni e a UAB como estratégias de EAD na expansão do ensino superior. Pro-Posições, Campinas, v. 20, n. 2, p. 205-222, maio/ago. 2009. Disponível em: TTP://www.scielo.br/pdf/pp/v20n2/v20n2a13.pdf. Acesso em: 1 jun. 2013.

A formação de professores a distância nas agendas governamentais (PNEs) e nos "espaços vazios." Revista Eletrônica de Educação, São Carlos, v. 8, n. 1, p. 56-76, jan./ abr. 2014.

; CAMARGO, Arlete Maria Monte de; OTRANTO, Celia Regina; CASTANHEIRA, Maurício; MAUÉS, Olgaises Cabral. Educação tecnológica, formação de professores e educação a distância como políticas de expansão da educação superior no Brasil Pós-LDB/96. Série-Estudos, Campo Grande, n. 30, p.93-116, jul./dez. 2010.

MOROSINI, Marília; FRANCO, Maria Estela Dal Pai. Questões transversais na expansão da educação brasileira pós-LDB. In: MANCEBO, Deise; BITTAR, Mariluce; CHAVES, Vera Lúcia Jacob (Org.). Educação Superior: expansão e reformas educativas. Maringá: Eduem, 2012. 
Profa. Dra. Olgaíses Cabral Maués Universidade Federal do Pará| UFPA Instituto de Ciências da Educação Pesquisadora do Grupo de Estudos de Políticas Educacionais, Formação de Professores e Trabalho Docente | GETRADO

"Estado, Educação e Sociedade"

Pesquisadora da Rede Universitas $\mid \mathrm{Br}$ Pesquisadora do Observatório da Educação "Políticas de Expansão da Educação Superior no Brasil" E-mail | olgaises@uol.com.br

Profa. Dra. Stella Cecilia Duarte Segenreich Universidade Católica de Petrópolis Instituto de Teologia e Humanidades Pesquisadora da Rede Universitas | Br Pesquisadora do Observatório da Educação "Políticas de Expansão da Educação Superior no Brasil"

Profa. Dra. Celia Regina Otranto Universidade Federal Rural do Rio de Janeiro | UFRRJ Instituto de Educação Departamento de Teoria e Planejamento de Ensino Pesquisadora da Rede Universitas | $\mathrm{Br}$ Pesquisadora do Observatório da Educação "Políticas de Expansão da Educação Superior no Brasil" E-mail | celiaotranto@terra.com.br

Recebido 11 set. 2014 Aceito 16 dez. 2015 